\title{
ESPECULAÇÃO SOBRE A TAXA DE INFECÇÃO DA DIFTERIA NO MODELO ESTOCÁSTICO SIMPLES DE EPIDEMIA
}

IJAVRADOR, M. A. S. \& SANCHES, O. Especulação sobre a taxa de infecçăo da diftcria no Modelo Estocástico Simples de Epidemia. Rev. Saúde públ., S. Paulo, $18: 51-5,1984$.

RESUMO: Com base em um programa em linguagem Fortran, utilizando a técnica de simulação em computador e através das pressuposições do Modelo Estocástico Simples de Epidemia, é estabelecida uma conjectura a respeito de valores para a taxa de infecção para a difteria, a partir de ocorrência de casos em um domicílio de cinco pessoas.

UNITERMOS: Modelo Estocástico. Difteria, Simulação.

\section{MODELOS MATEMATICOS EM EPIDEMIAS}

$$
\text { E SIMULAÇÃO }
$$

Bailey $^{3}$ (1975) acentua o seguinte fato:

"Em 30 cie abril de 1870 o matemático suiço Daniel Bernouilli apresentou um trabalho à Academia Real de Ciências de Paris no qual provavelmente pela primeira vez, foi utilizado um modelo matemático para estudar a dinâmica populacional de uma doença. Bernouilli estava interessado especificamente em estudar a mortalidade causada pela variola e avaliar os riscos e vantagens associadas com a inoculaçāo preventiva, uma técnica controvertida que, antes da descoberta da vacinação, já atraia muitas atenções. $O$ trabalho matemático teórico desenvolvido não só abordou um problema real de saúde mas as conclusões foram todas relacionadas diretamente com as açōes práticas".

Sabe-se hoje, de modo bastante consciente, que a questão clínica de diagnóstico, prognóstico e eficiência de tratamento, em geral, depende da interpretação de dados estatísticos adequados.

Em doenças infecciosas e parasitárias há interesse em desenvolver modelos matemáticos em função da luz que podem lançar a respeito de alguns mecanismos biológicos, tais como o ciclo de vida de um parasito. Alternativamente pode-se usar estes modelos para estudar fenômenos populacionais em larga escala, de relevância imediata, ou para estabelecer alguma medida relacionada a problemas de saúde pública ou de natureza social. Em particular, desejamos conhecer mais profundamente os mecanismos de transmissão e espalhamento de doenças infecciosas, estabelecer tentativas de se prever o curso de uma epidemia ou, ainda, tentar estabelecer densidades limites de populações que podem ser atingidas por uma doença antes da eclosão de uma epidemia.

* Do Departamento de Ciências Exatas da Faculdade de Ciências Agrárias e Veterinárias da UNESP - Campus de Jaboticabal - Rodovia Carlos Tonanni, $\mathrm{Km} 5$ - 14870 - Jaboticabal, SP - Brasil.

** Do Departamento de Enfermagem Geral e Especializada da Escola de Enfermagem da USP - Campus de Ribeirão Preto - 14100 - Ribeirăo Preto, SP - Brasil. 
LAVRADOR, M.A.S. \& SANCHES, O. Especulação sobre a taxa de infecção da difteria no Modelo Esticástico Simples de Epidemia. Rev. Saúde públ., S. Paulo, 18:51-5, 1984.

Neste sentido, o desenvolvimento de modelos matemáticos, ainda que criticados por sua simplicidade ou ausência de abrangência, tem-se mostrado ferramenta útil que pode auxiliar na tomada de decisões, para ajudar a avaliar as consequiências da escolha entre algumas estratégias alternativas disponiveis, na escolha de esquemas de imunização, na alocação ótima de recursos escassos ou na melhor combinação de técnicas de controle e erradicação.

Um modelò matemático corretamente compreendido e aplicado tem o mesmo status lógico de qualquer outra hipótese científica e deve ser manipulado e justificado de acordo com os mesmos critérios, Bailey ${ }^{2}$.

Com pequenos grupos, como familias individuais, é possivel obter dados aproximadamente homogêneos de um grande número de tais unidades. A análise dos padrões epidêmicos observados, com base em modelos matemáticos específicos, permite a estimação numérica de parâmetros epidemiológicos de importância, tais como a probabilidade de infecção, valores esperados, variâncias entre outros; assim como testes estatísticos adequados permitem verificar a adequação do modelo através da concordância ou pão entre os dados observados e as proposições hipotetizadas.

Nas situações onde os dados necessários mostram-se em pequena quantidade, a técnica de simulação em computador tem-se mostrado de grande utilidade na elucidação, predição ou estimação de parâmetros de interesse.

$\mathrm{O}$ advento dos computadores de alta capacidade de armazenamento de dados e alta velocidade de resolução tornou possível investigaçóes extensivas de processos simulados, isto é, o computador produz um grande número de realizaçōes artificiais de um processo de interesse, baseado em unn modelo matemático e pode, se assim o desejarmos, calcular médias, variâncıas, probabilidades de ocorrência de um dado evento entre outras, com um grau relativamente alto de precisão.
A técnica de simulação é, essencialmente, um processo de amostragem e 0 que se consegue, em resumo, num estudo de simulação, é a realização de um número muito grande de reproduções do processo $\mathrm{cm}$ investigação e, a partir daí, o cálculo de quantidades de interesse nessa amostra limitada de "quase observaçōes".

Esta técnica tem sido aplicada a ampla variedade de estudos biológicos e médicos, incluindo a interação entre espécies, o comportamento evolutivo de sistemas genéticos, o espalhamento e a recorrència de processos epidêmicos, o funcionamento de circuitos neuronais e outros sistemas fisiológicrs (Bailey)2.

Neste trabalho, pretende-se, usando a técnica de simulação e alguns resultados teóricos do modelo estocástico simples de epidemia, estabelecer alguma especulação a respeito da taxa de infecção para a diftetia, em uma situação específica.

\section{CONSIDERAÇOES SOBRE O MODELO}

\section{ESTOCASTICO SIMPLES DE EPIDEMIA}

Lavrador 6 , entre outros, estudou o modelo estocástico simples de epidemia em suas versões deterministica e estocástica, assim como possíveis aplicações.

No modelo simples de epidemia admite-se que os indivíduos infecciosos não são removidos da população (por morte, imunidade ou isolamento) a qual é constituída por susceptiveis e infecciosos, homogeaneamente misturados, permanecendo com o mesmo número inicial de indivíduos até o fim da epidemia. Admite-se ainda, como pressuposição, que o período de latência seja nulo e que o período de infecciosidade continue até que todos tenham adquirido a infecção, e que cada infecção ocorra de acordo com uma distribuição de Poisson. Segundo Bailey ${ }^{3}$, este modelo pode ter relativo sucesso em moléstias cujo período de latência seja curto, com alta infecciosidade, mas não suficientemente sério para levar à morte, como por exemplo nas infecções brandas do trato respiratório superior. 
LAVRADOR, M.A.S. \& SANCHES, O. Especuia ção sobre a taxa de infecção da difteria no Modelo Esticástico Simples de Epidemia. Rev. Saúde públ., S. Paulo, 18:51-5, 1984.

No modelo estocástico,admite-se que em um certo intervalo de tempo $\Delta \mathrm{t}$ a única transição possivel é o acréscimo de um infeccioso com o decréscimo de um susceptível. Num instante inicial $t_{0}=0$ a população $e$ constituída de " $a$ " infecciosos e ( $\mathrm{N}$ - a) susceptíveis. Designando as variáveis aleatórias $X(t)$ e $Y(t)$ como o número de susceptiveis e infecciosos, respectivamente, em um dado instante $t$ e conhecendo-se a taxa de infecção $\beta$, o modelo estocástico simples de epidemia permite encontrar $P[X(t)=r]=P_{r}(t)$ a probabilidade que o número de susceptiveis seja jgual a $r,[r=0,1,2 \ldots(N-a)]$.

Segundo Bailey ${ }^{3}$, este modelo pode mostrar-se adequado para o estudo de doenças tais como a escarlatina e a difeteria, em estudo com núcleos familiares.

\section{APLICAÇAO À DIFTERIA}

Com base na resolução de Severo ${ }^{7}$ para o modelo estocástico simples de epidemia, desenvolveu-se um programa em linguagem Fortran, para um computador EDISA-301, que permite obter as probabilidades $\mathrm{P}_{\mathbf{r}}(t)$, - número esperado de infecciosos e seu desvio padrão (Lavrador) ${ }^{6}$.

Devido à falta de informações a respeito da taxa de infecção para a difteria, na literatura disponivel, foram obtidos no Centro de Saúde I de Ribeirão Preto, SP, dados sobre um surto ocorrido em um domicílio constituído de cinco indivíduos, no ano de 1981. Ocorreram, neste domicílio, dois casos de difteria, sendo que o segundo caso surgiu quatro dias após os sintomas do primeiro caso. Como os familiares mostraram-se ignorantes quanto a antecedentes de vacinação, supôs-se que os mesmos eram susceptiveis, de modo que trabalhou-se com uma população constituída por um caso inicial e quatro susceptiveis.
$\mathrm{Na}$ impossibilidade de poder usar o método de estimação proposto na literatura (Bailey) $^{3}$, pois só contava-se com uma amostra, foi usado o método de ensain e erro para se obter um valor da taxa de infecção $\beta$, descrito a seguir.

A partir dos trabalhos de Armijo-Rojas ${ }^{1}$, Cvjetanovic e col. ${ }^{4}$, Frost 5 e Veronesi ${ }^{6}$ considerou-se que para situações endêmicas um valor subjetivo para $\beta$ deveria ser maior que $10^{-4}$. Tomou-se esse valor com um limite inferior e gerou-se, em computador, vários surtos epidêmicos, em famílias de cinco individuos, sendo um infeccioso inicial e quatro susceptiveis, de acordo com as proposições do modelo estocástico simples de epidemia, a fim de se identificar alguns surtos que estivessem mais próximos-do ocorrido para, então, ter idéia a respeito de $\beta$ para o surto ocorrido naquele domicílio.

A unidade de tempo foi tomada como igual a 4 dias, periodo de tempo entre 0 surgimento dos sintomas nos dois casos. Geraram-se, no computador, surtos epidêmicos sucessivos para os seguintes valores de taxas de infecção: 0,$0001 ; 0,001 ; 0,01$; 0,$1 ; 0,2 ; 0,25 ; 0,3 ; 0,4$ e 0,5 , conforme a Figura.

Desde que a diferença de tempo entre a ocorrência do caso inicial e do segundo caso foi tomada com unidade de tempo, localizamos para quais valores da taxa de infecção os surtos, gerados em computador, mais se aproximavam do caso real em uma unidade de tempo, o que nos forneceu $o$ valor para a taxa de infecçăo entre $0,2 \mathrm{e}$ 0,25 .

\section{DISCUSSAO E CONCLUSAO}

O valor de $\beta$, a taxa de infecção para a difteria, que obteve-se $(0,20 \leqslant \beta \leqslant 0,25)$ pelo método de ensaio e erro, através de 
LAVRADOR, M.A.S. \& SANCHES, O. Especuliaçăo sobre a taxa de infecção da difteria no Modelo Esticástico Simples de Epidemia. Rev. Saúde públ., S. Paulo, 18:51-5, 1984.

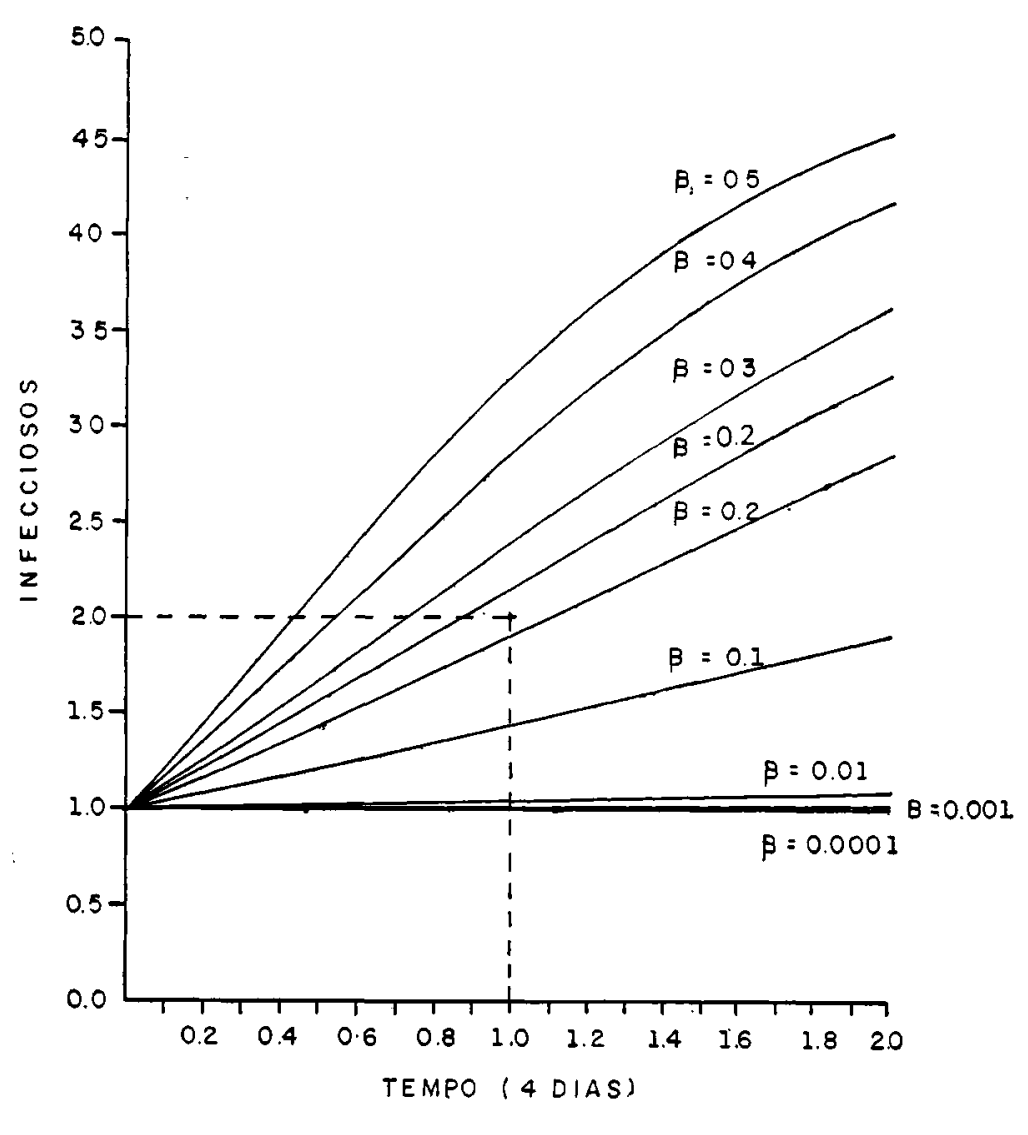

Figura: Valores esperados de infecciosos.

simulação, vale somente para o caso desse surto particular ocorrendo nesse domicílio.

Se existisse dados disponíveis para vários grupos familiares, o correto seria empregar método de estimação descrito em Bailey ${ }^{3}$, ou uma possivel variação do mesmo. Neste caso, com um forte suporte estatístico, tal estimativa se prestaria a fornecer um valor menos particular e especulativo para a taxa de infecção no caso de difeteria.

Acredita-se, no entanto, que, a par de divulgar um modelo matemático e a técnica de simulação em um processo epidêmico, o presente trabalho contribui no sentido de se ter um idéia da ordem de grandeza do valor desta taxa. 
LAVRADOR, M.A.S. \& SANCHES, O. Especulação sobre a taxa de infecção da difteria no Modelo Esticástico Simples de Epidemia. Rev. Saúde públ., S. Paulo, 18:51-5, 1984

LAVRADOR, M. A. S. \& SANCHES, O. [Speculation on the diphtheria infection in the Simples Stochastic Epidemic Model]. Rev. Saúde públ., S. Paulo, 18:51-5, 1984.

ABSTRACT: An epidemic outbreak according to a simple stochastic epidemic model, it was sinulate, by means of a Fortran Programme, to formulate conjectures on infection rate values in the case of diphtheria in a household of five.

UNITERMS: Probability. Diphtheria. Simulation.

\section{REFERENCIAS BIBLIOGRAFICAS}

1. ARMIJO-ROJAS, R. Epidemiologia. B enos Aires, Inter-Médica Editorial, 1976, v. 2.

2. BAILEY, N.T.J. The mathematical approach to biology and medicine. London, John Wiley \& Sons, 1967.

3. BAILEY, N.T.J. The mathematical theory of infectious discases and its applications. London. Charles Griffin \& Co., 1975.

4. CVJETANOVIC, B.; GRAB, B. \& VEMURA, K. Dinamics of acute bacterial diseases. Geneva, World Health Organization, 1978.

5. FROST, W.H. A contribution to epidemiological method. New York. The Common Wealth Fund, 1941.
6. LAVRADOR, M.A.S. Alguns modelos matemáticos básicos em epidemias. Ribeirão Preto, 1982. [Disertação de Mestrado Faculdade de Medicina de Ribeirão Preto da USP].

7. SEVERO, N.C. Two theorems of differential: difference equation and applications to epidemic theory. J. appl. Probab., 4:271-80, 1967.

8. VERONESI, R. Doencas infecciosas e parasitarias. Rio de Janeiro, Editora Guanabara Koogan, 1967.

Recebido para publicação em 09/02/1983

Reapresentado em 20/10/1983

Aprovado para publicasäo em 24/10/1989 